\title{
Implementing Process Innovations
}

\section{The Benefits of Combining Delegative-Participative With Consultative-Advisory Leadership}

\author{
Diana E. Krause \\ University of Western Ontario, Canada \\ Diether Gebert \\ Korea National University, Seoul, South Korea \\ Eric Kearney \\ Technical University, Berlin, Germany
}

\begin{abstract}
Previous research leaves open which facets of leadership foster the implementation of process innovations. In this study, the authors analyze the effects of delegative-participative and consultative-advisory leadership, respectively, on the implementation success of process innovations. They argue that each of these leadership behaviors entails specific advantages and risks and that therefore the two patterns complement each other. The sample consisted of managers from different organizations. Although the posited main effects of both delegativeparticipative and consultative-advisory leadership are confirmed, the significant interaction between these two leadership styles has a different direction than the authors hypothesized.
\end{abstract}

Keywords: innovation; implementation; leadership; delegation; participation; consultation

$\mathrm{C}$ ontemporary organizations need to be innovative to maintain a competitive advantage. Thus, organizations increase their efforts to generate and implement new products or processes in their work units. Although the generation of ideas has been addressed extensively in the literature (Amabile, Conti, Coon, Lazenby, \& Herron, 1996), there are very few studies that analyze the implementation of innovations (e.g., Axtell et al., 2000) despite the fact that it is often the implementation phase that poses the greatest challenge for organizations. Moreover, the extant literature primarily focuses on product innovations and not process innovations. Against the backdrop of these shortcomings of the current literature on innovation, our study focuses on the implementation of process innovations in organizations. Our main question is: What facet of leadership behavior increases the chances of successfully implementing a process innovation, and by what mechanisms does this success come about? We focus on process innovations-namely, novel solutions in generating goods and services-such as the introduction of a new software, e-commerce application, project management approach, personnel evaluation system (e.g., $360^{\circ}$ feedback), or goal-setting instrument (e.g., balanced score card).

Leadership has frequently been investigated as a determinant of innovativeness (Burpitt \& Bigoness, 1997; Manz, Bastien, Hostager, \& Shapiro, 1989; Oldham \& Cummings, 1996; Scott \& Bruce, 1998; Tierney, Farmer, \& Graen, 1999). The results reported in this literature are markedly heterogeneous (West, 2002). In part, this may be due to the conceptualizations of leadership in the literature, many of which have been unsatisfactory for predicting leadership success (Yukl, 2006). As a step forward, we suggest the analysis of the effects of two important aspects of leadership on innovation: first, delegative-participative leadership and second, consultative-advisory leadership.

Authors' Note: We thank two anonymous reviewers for their constructive feedback that helped to improve an earlier version of this manuscript. 


\section{Theory}

\section{Implementation Success of Process Innovations as a Function of Delegative- Participative Leadership and of Consultative-Advisory Leadership}

The main argument made here is that the implementation success of process innovations is a function of both delegative-participative leadership and consultative-advisory leadership (see Figure 1). We define the implementation success of a process innovation by the degree to which the work unit is perceived as being both more effective and efficient after the innovation's implementation.

In theory, leadership is conducive to the implementation of innovations to the degree that it prompts the subordinates to put novel and fruitful ideas into action as intended (Lewis \& Seibold, 1993). Ideally, this will improve the effectiveness and efficiency of the work unit. The first facet of leadership we study here, delegative-participative leadership, refers to the degree to which the subordinates (who may in turn also be leaders with respect to others) are given the chance to influence the way in which an innovation is implemented and how the respective process innovation is put into action in their field of responsibility. Delegative-participative leadership grants subordinates a say (participation) and discretionary authority (delegation) with respect to the implementation. There is widespread agreement that a delegative-participative leadership fosters creative, innovative performance (Anderson \& King, 1993; Axtell et al., 2000; Manz et al., 1989; Mumford, Scott, Gaddis, \& Strange, 2002). Delegative-participative leadership raises the degree of subordinates' perceived situational control (Krause, 2004). Increases in perceived situational controlnamely, the subordinates' appraisal that the work setting is indeed susceptible to change-attenuates the degree to which the changes induced by the process innovation are perceived as threatening (Lazarus, 1991). Granting opportunities to wield influence is likely to lead subordinates to interpret the leadership process as being fair, thus procedurally raising the acceptance of process innovations (cf. Brockner \& Siegel, 1996). Moreover, these processes enhance intrinsic motivation for implementation. Increasing the degree of situational control fosters the subordinates' motivation to initiate initiatives and assume responsibility with respect to filling in the details of how a more broadly defined process innovation should be
Figure 1

\section{Implementation Success as a Function of Both Delegative-Participative and Consultative-Advisory Leadership}

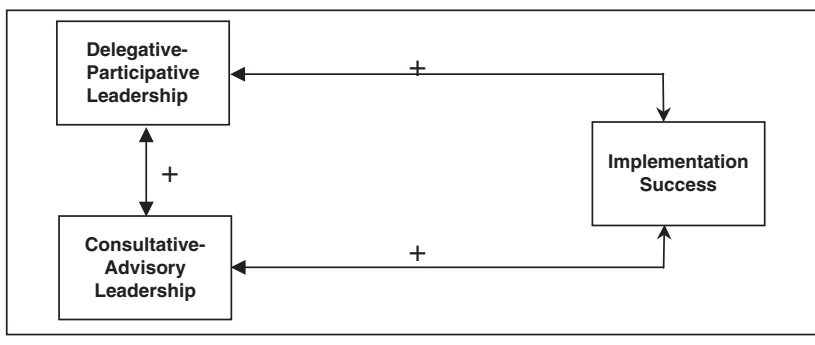

implemented (Frese \& Zapf, 1994). This facilitates the adaptation of a process innovation to a specific context and, hence, its functionality. This reasoning leads to:

Hypothesis 1: Delegative-participative leadership is positively associated with the implementation success of process innovations.

Furthermore, we assume that the implementation of process innovations is enhanced by a second leadership facet, consultative-advisory leadership. We define consultative-advisory leadership as the degree to which the leader influences the follower by providing advice, professional guidance, and background information about the process innovation. By thus explicating the objectives of and the prerequisites for the successful implementation of a process innovation, consultativeadvisory leadership enables a fine-tuning of the subordinate's cognitive task model. Sharing background information is one way of expressing appreciation for a subordinate (Bauer \& Green, 1996; Tyler, Degoey, \& Smith, 1996), and it facilitates the discussion of implementation-related issues. Moreover, offering advice, professional guidance, and advisory background information furthers a deeper understanding of the process innovation on the part of the subordinate, in turn reducing the tasks' ambiguity. By thus providing a sense of orientation and reducing ambiguity, it becomes more likely that a follower will accept the innovation. Promoting acceptance in turn increases the likelihood that a subordinate will actively support the process innovation and contribute to the success of its implementation. Finally, leadership that provides advice and orientation fosters the cognitive adaptation of a process innovation to different contexts in other work units. Thus, 


\section{Table 1}

Advantages and Risks of Both Delegative-Participative and Consultative-Advisory Leadership

\begin{tabular}{|c|c|c|c|}
\hline \multicolumn{2}{|c|}{ Delegative-Participative Leadership } & \multicolumn{2}{|c|}{ Consultative-Advisory Leadership } \\
\hline Advantages & Risks & Advantages & Risks \\
\hline $\begin{array}{l}\text { Increase in } \\
\text { perceived } \\
\text { situational } \\
\text { control }\end{array}$ & $\begin{array}{l}\text { Frequent } \\
\text { mis- and } \\
\text { reinterpretations }\end{array}$ & $\begin{array}{l}\text { More discussions } \\
\text { about problems } \\
\text { inherent in the } \\
\text { implementation }\end{array}$ & $\begin{array}{l}\text { Increased } \\
\text { probability of } \\
\text { reactance }\end{array}$ \\
\hline $\begin{array}{l}\text { Increased } \\
\text { procedural } \\
\text { fairnes }\end{array}$ & $\begin{array}{l}\text { Increased } \\
\text { relationship } \\
\text { conflicts }\end{array}$ & $\begin{array}{l}\text { Increased } \\
\text { sense-making } \\
\text { to distribute }\end{array}$ & $\begin{array}{l}\text { Increased } \\
\text { reluctance } \\
\text { information } \\
\text { to others }\end{array}$ \\
\hline $\begin{array}{l}\text { Increased } \\
\text { intrinsic } \\
\text { motivation to } \\
\text { implement }\end{array}$ & $\begin{array}{l}\text { Increased } \\
\text { need for } \\
\text { coordination }\end{array}$ & Less ambiguity & \\
\hline $\begin{array}{l}\text { Increased } \\
\text { implementation- } \\
\text { related personal } \\
\text { responsibility }\end{array}$ & & $\begin{array}{l}\text { Increased } \\
\text { acceptance of } \\
\text { the innovation }\end{array}$ & \\
\hline
\end{tabular}

Hypothesis 2: Consultative-advisory leadership is positively associated with the implementation success of a process innovation.

\section{Risks of Delegative-Participative Leadership and of Consultative-Advisory Leadership and the Complementarity of the Approaches}

Delegative-participative leadership is not just connected with the aforementioned advantages but also with specific risks (Sheremata, 2000). Subordinates may misinterpret the freedoms they have been granted. In his or her work, a person may implement the process innovations in ways that harm colleagues or the work unit as a whole. Subsequently, such idiosyncratic reinterpretations can give rise to relationship conflicts (Jehn, 1995). Moreover, it can be assumed that delegative-participative leadership entails a higher need for coordination. Freedoms must be clearly defined; they require restrictions. Whereas delegative-participative leadership increases the risk of misinterpretations concerning a process innovation, consultative-advisory leadership can compensate the thus spawned negative effects by providing information regarding the objective and purpose of the process innovation.
Conversely, consultative-advisory leadership also has its risks. For example, a subordinate may construe the leader's behavior as patronizing, which in turn may lead to relationship conflicts (Jehn, 1995) and to reactance (Brehm, 1966). If a follower exhibits reactance, this is likely to decrease his or her motivation to feel responsible for implementing the process innovation. Moreover, he or she may increasingly resist sharing his or her contextual knowledge that is relevant to a successful implementation. As was the case with delegative-participative leadership, leading others by providing advice and orientation thus entails risks that need to be addressed. This could be done by fostering the independence of the subordinate. In sum, two points become obvious. First, both leadership patterns discussed here are connected with advantages and risks (see Table 1).

Second, both leadership patterns are complementary. Leading others by providing advice and orientation reduces the specific risks associated with delegative-participative leadership, which consist of a subordinate's mis- or reinterpretations of the process innovation. Conversely, delegative-participative leadership attenuates the specific disadvantages connected with consultative-advisory leadership, which comprise displays of reactance on the part of the subordinate. Because each of these two leadership facets can 
compensate the risks of the respective other set of leadership behaviors, it is reasonable to assume that with respect to implementing innovations, these leadership styles will have the greatest beneficial effect when they are combined. By contrast, if only one of these patterns is used, the results will most likely be suboptimal. Concomitantly employing both delegativeparticipative leadership and consultative-advisory leadership brings to fruition the full positive potential of each of these leadership styles. Thus, these behavioral patterns can be viewed as functionally equivalent. We therefore posit,

Hypothesis 3: Consultative-advisory leadership moderates the relationship between delegative-participative leadership and the implementation success of product innovations. When levels of consultative-advisory leadership are high, this relationship is positive, whereas when levels of consultative-advisory leadership are low, this relationship is negative.

\section{Method}

\section{Sample and Procedure}

Managers $(N=388)$ from German organizations of different sizes and sectors were surveyed. The process innovations were treated as critical incidents (Flanagan, 1954), which has the advantage of a higher context specificity (see Krause \& Kearney, 2006) and thus more valid answers in comparison to other methods. The managers were requested to recall a specific process innovation in their work unit and to describe this innovation in a qualitative and quantitative manner. They were then asked to answer questions about how they as managers were led by their immediate superior during the innovation process and to rate the degree to which the implementation was successful.

The managers were recruited for the study in three different ways. First, letters were sent to randomly selected persons in leadership positions whose names and addresses are contained in a German catalogue (called Hoppenstedt) that features 55,700 managers. Second, at airports, exhibitions, conferences, and leadership training courses, managers were approached in person and asked for their participation directly. Third, questionnaires were handed to managers by the heads of the personnel departments of various organizations. We had business-related contacts with those heads of the personnel departments and asked them if they would be willing to distribute the questionnaire to the managers working in their departments.
After a brief personal communication concerning topic and goals of the study, the questionnaire and attached letter were either handed to the participants directly along with a self-addressed stamped envelope or sent via regular mail or e-mail. The questionnaires were returned anonymously to our university via regular mail in a sealed envelope. Participation in the study was voluntary, and no remuneration was offered. In return for answering the questionnaire, those participants who were interested were supplied with aggregated and anonymous information regarding the descriptive results of the study. The strict anonymity policy that prevented us from sending reminders to the contacted managers who had not yet responded and the length of the questionnaire militated against obtaining a high response rate. However, our final response rate of $24 \%$ might indicate that selection effects of the queried managers had occurred. Hence, we examined the possibility of a response bias with respect to industry sector and organization size. Contrary to what would have been expected in the case of a response bias, our analysis revealed that our participants constituted a sufficiently representative sample of German managers. Our results can therefore be generalized to managers at different hierarchical levels and in different industries and fields of specialization.

The respondents ranged in age from 22 to 64 years ( $M=39$ years, 6 months; $S D=9$ years, 9 months $)$ and represented several levels of hierarchy (21\% group leaders, $23 \%$ department heads, $12 \%$ division heads, $23 \%$ area heads, $16 \%$ general managers, $5 \%$ members of the managing board) and areas of expertise (27\% from marketing and sales, $22 \%$ from business administration, $21 \%$ from personnel and organization design departments, $9 \%$ from production, $7 \%$ from research and development, $6 \%$ from technical support, andbecause of missing data- $8 \%$ from unknown areas). Of the respondents, $82 \%$ were men. This overrepresentation of men reflects the current gender disparity in German organizations. The sectorial distribution of the managers in the sample was broad (19\% in banks and insurance companies; $18 \%$ in telecommunications, data processing, or the media; $16 \%$ in services; $8 \%$ in construction; $8 \%$ in mechanical engineering and the automotive industry; $8 \%$ in trade; $5 \%$ in the chemical industry; $5 \%$ in utility companies; $2 \%$ in the food industry; and-again because of missing data$11 \%$ from unknown industries). The distribution of the managers with respect to the size of their respective organization showed that most of the managers $(81 \%)$ worked either in medium-sized companies (with up to 500 employees) or large companies (with 501 to 5,000 employees). 


\section{Measures}

Measurement of leadership. The instruction in the part of the questionnaire pertaining to leadership was, "Please evaluate the extent to which your superior used the following leadership strategies during the innovation process." Leadership was assessed using a 6-item scale (7-point Likert scale, ranging from $1=$ strongly agree to 7 = strongly disagree), whose construct and criterion validity have been shown to be satisfactory (Krause, 2004). The leadership scale was developed in three steps. First, we developed a pool of 82 leadership items pertaining to process innovations. In a pretest, we calculated item characteristics and scale dimensionality and reliability. Based on the results of the pretest, we selected 18 items for our final leadership scale. Second, we tested the structure of this scale in a different sample and found five leadership components (Krause, 2004). Third, we evaluated these five leadership facets with respect to their relevance concerning our criterion implementation success. We identified two leadership patterns that we consider to be most important in regard to implementation success, namely, delegative-participative leadership and consultative-advisory leadership.

We checked the factor structure of the employed leadership scale by means of a principal components analysis with varimax rotation. The results confirmed our assumption of two leadership factors, which together explained $71 \%$ of the variance. The items of the first factor were "During the innovation process, my superior gave me many opportunities to contribute to shaping this innovation in my area of responsibility;" "During the innovation process, my superior granted me autonomy, degrees of freedom, and decisionmaking authority;" "During the innovation process, my superior presented me with a fait accompli (reversed)." This factor is interpretable as delegativeparticipative leadership (Cronbach's $\alpha=.82$ ). The items of the second factor were "During the innovation process, my superior helped me in solving complicated issues;" "During the innovation process, my superior shared with me his or her professional ideas;" "During the innovation process, my superior provided me with all the important information." This factor can be construed as consultative-advisory leadership $(\alpha=.70)$.

Measurement of implementation success. Implementation success was measured with four newly developed items on a 7-point Likert scale, ranging from $1=$ unsuccessful to $7=$ successful . The items
Table 2

Means, Standard Deviations, and Correlations

\begin{tabular}{|c|c|c|c|c|c|c|}
\hline Variable & $M$ & $S D$ & 1 & 2 & 3 & 4 \\
\hline 1. Job tenure & 3.64 & 1.24 & - & & & \\
\hline 2. Degree of innovation & 4.78 & 1.31 & -.01 & - & & \\
\hline $\begin{array}{l}\text { 3. Delegative-participative } \\
\text { leadership }\end{array}$ & 5.20 & 1.64 & -.05 & $.21 * * *$ & - & \\
\hline $\begin{array}{l}\text { 4. Consultative-advisory } \\
\text { leadership }\end{array}$ & 4.13 & 1.51 & .04 & $.11 *$ & $.32 * * *$ & - \\
\hline 5. Implementation success & 5.23 & 1.33 & .07 & $.15^{* *}$ & $.49 * * *$ & $.35^{* * * *}$ \\
\hline
\end{tabular}

Note: $N=388$ managers. Pearson correlations. Two-tailed significance tests.

$* p<.05 . * * p<.01 . * * * p<.001$.

were "How would you rate the overall success of the implementation of the process innovation?" "How would you rate the success of the implementation of the process innovation with respect to the effectiveness and efficiency of your work unit?" "How would you rate the success of the implementation of the process innovation with respect to your initial hopes and fears?" "How would you rate the success of the implementation of the process innovation with respect to unexpected side effects?" All of these items loaded on one factor $(\alpha=.91)$ that explained $79 \%$ of the variance.

Control variables. We included job tenure (which ranged from 1 year to more than 10 years) and degree of innovation as control variables. The respondents' job tenure can be interpreted as experience in their jobs, which may have an impact on the level of implementation success. Furthermore, the degree of innovation needs to be controlled because there is reason to believe that implementation barriers rise with increasing degree of innovation. The degree of innovation (7-point Likert scales) was operationalized by three criteria: scope ("The chosen new process differs strongly from the processes employed by my organization in the past"), initiative ("My work unit was the first to develop and/or implement this novelty"), and ramifications ("Through this novelty, the extant structures of power, control, and competencies were altered significantly"). These items loaded on one factor that explained $45 \%$ of the variance. The reliability of this scale was modest $(\alpha=.60)$.

\section{Results}

Table 2 presents the means, standard deviations, and intercorrelations of the study variables. As expected, 
Table 3

Results of the Hierarchical Regression Analysis of Implementation Success on Delegative-Participative Leadership, Consultative-Advisory Leadership, and the Interaction of These Leadership Patterns

\begin{tabular}{lc}
\hline & $\begin{array}{c}\text { Criterion } \\
\text { Implementation } \\
\text { Success } \\
\beta\end{array}$ \\
& \\
\hline Control variables & .08 \\
Job tenure & .04 \\
Degree of innovation & \\
Predictors & $.75^{* * *}$ \\
Delegative-participative leadership & $.70^{* * *}$ \\
Consultative-advisory leadership & $-.71^{* *}$ \\
Interaction of both leadership patterns & .54 \\
Values of the model & $.30(.29)$ \\
$R$ & $.03 * * *$ \\
$R^{2}$ ( $R^{2}$ adjusted) & \\
$\Delta R^{2}$ for the interaction of both & $39.14 * * *$ \\
$\quad$ leadership patterns & 6,374 \\
& \\
& \\
$N$ &
\end{tabular}

Note: $N=381$ due to missing values in the variables. $B=$ standardized regression coefficient. $R=$ multiple correlation coefficient. $R^{2}=$ explained variance.

$* * p<.01 . * * * p<.001$.

Figure 2

Interaction: Consultative-Advisory Leadership as a Moderator of the Relationship Between Delegative-Participative Leadership and the Implementation Success of Process Innovations

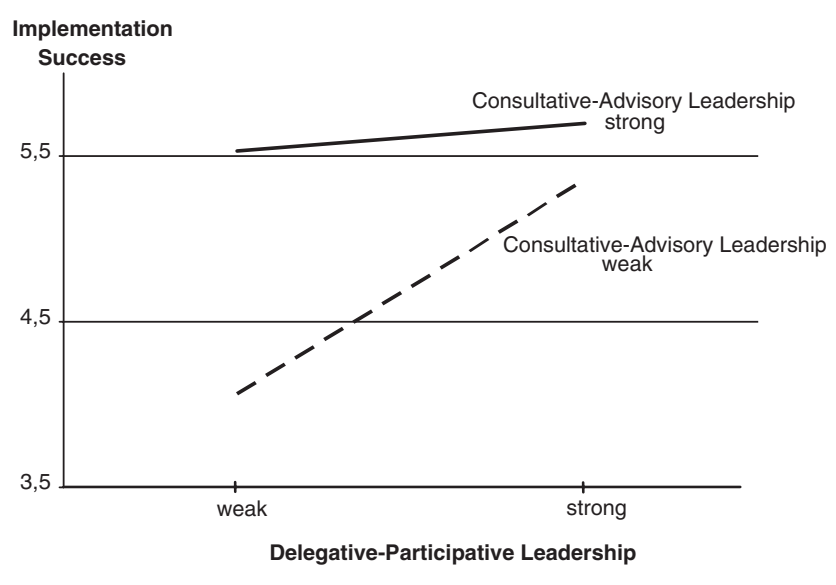

Figure 3

Interaction: Delegative-Participative Leadership as a Moderator of the Relationship
Between Consultative-Advisory Leadership
and the Implementation Success of
Process Innovations

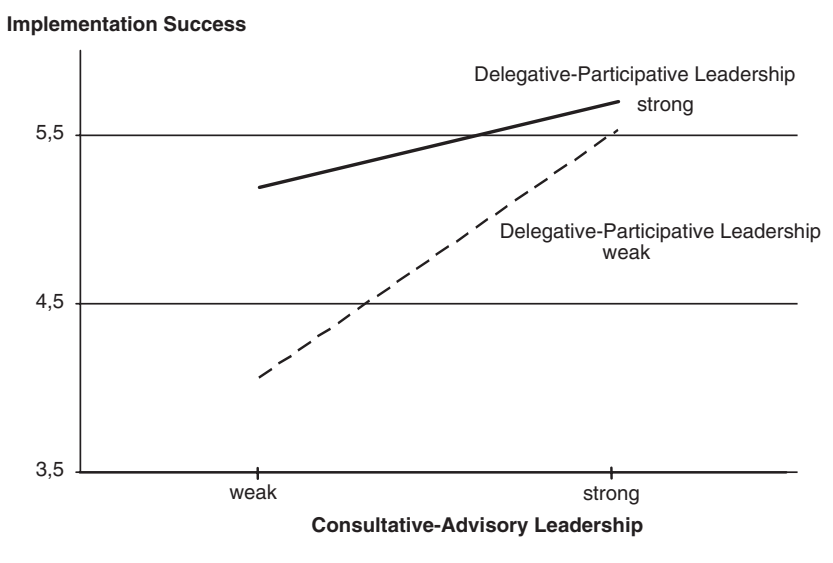

both leadership facets were significantly positively related to success regarding the implementation of process innovations. We had argued earlier that each of these two leadership patterns is connected with undesired secondary effects and that the respective other strategy is necessary as a countermeasure to compensate these negative effects. To test this assumption, we conducted a hierarchical regression analysis of implementation success. In the first step, we entered job tenure and degree of innovation as control variables. We added delegative-participative leadership and consultative-advisory leadership in the second step of the regression. Finally, in the third step, we entered the interaction effect of both leadership patterns. Table 3 summarizes the results.

The regression weights of the control variables were not significant. In support of Hypotheses 1 to 3 , adding delegative-participative leadership and consultative-advisory leadership as main effects in the second step explained a significant portion of the variance. Entering the interaction term of both leadership components in the third step likewise yielded a significant change in the amount of variance explained (see Table 3). Specifically, the interaction explained an additional $3 \%$ of the implementation success variance over and above the variance explained by the main effects. Together, the main effects and the interaction effect explained $30 \%$ of the differences regarding the success of the process innovation implementation. 
This is fairly substantial when considering that effectiveness and efficiency also depend on the quality and the potential of the process innovation itself. This amount of explained variance is also high in light of the fact that a common method variance might have occurred in this study-an aspect that we will discuss in the section on limitations.

Nevertheless, although the interaction effect is statistically significant, its direction is somewhat different than we had hypothesized. This is a surprising result that merits closer scrutiny. On the one hand, it appears to be the case that the highest level of implementation is evident when the levels of both leadership patterns are high. This is in line with our reasoning underlying Hypothesis 3: Combining both leadership patterns enables each leadership style to neutralize the discussed risks of the respective other set of leadership behaviors and vice versa. In this case-namely, when the levels of both leadership patterns are highthe respective advantages of each leadership style can be brought to full fruition.

On the other hand however, the results show that each of the two leadership styles is also conducive to success when the level of the respective other leadership pattern is low (see Figures 2 and 3). This finding contradicts our assumptions underlying Hypothesis 3 .

\section{Discussion}

\section{Contributions}

The present study makes two contributions to the research literature. First, with respect to successfully implementing process innovations, it underscores the importance of the interaction between delegativeparticipative and consultative-advisory leadership. Based on a literature review of single studies and metaanalyses and personal communication with colleagues who specialize in leadership, we think that this is one of the few studies that examine the contribution of the interplay of those leadership facets on implementation success. Previous studies of innovation have only investigated one of the two leadership components discussed here (e.g., Axtell et al., 2000) but not their interaction. We believe however that viewing either delegative-participative or consultative-advisory leadership in isolation neglects the complexity of organizational leadership in action. We therefore propose that a more complete understanding of the factors underlying implementation success can be gained by examining the interplay of these two sets of leadership behaviors.
Second, the results of the present study increase our knowledge of the implementation process as we examine the conditions of successful implementation regardless of the long-term effects of innovations. This is important because there are very few empirical studies of the implementation of process innovations. Nevertheless, some scholars have focused on the implementation of innovations in general. For instance, De Dreu (2006) showed that innovation (operationalized as the implementation of new procedures and methods and assessed in interviews of team supervisors) is a curvilinear function of task conflicts in management teams. Such studies do not explain however in what ways leadership may have either functional or dysfunctional effects on implementation success.

\section{Examining the Form of the Interaction Effect}

Examining the form of the interaction effect we identified promises to shed some light on important issues. Situations in which there is low delegativeparticipative leadership are hardly uncommon in organizational settings. During the implementation of process innovations, leaders are often themselves the recipients of nonnegotiable instructions issued by their superiors. Frequently, they pass the thus generated pressure on to their subordinates. In this constellation, high levels of consultative-advisory leadership may be particularly conducive to successful implementation phases. When a subordinate is presented with a fait accompli, providing background information and offering advice may make it possible to develop or retain his or her motivation to cooperate despite the clear-cut guidelines that offer little leeway in regard to how the work is to be done. Such leadership actions may be construed by subordinates as considerate behavior on the part of the leader and may thus counteract some of the negative motivational effects of centralized decisions. If this reasoning is correct, this would mean that consultative-advisory leadership does not act as a buffer against the risks of high levels of delegative-participative leadership but rather serves to counter the risks entailed by low levels of delegation and participation.

The situation is similar when there are low levels of consultative-advisory leadership, which may also occur frequently in organizations. Often, leaders may either not be present physically or not have the time to offer consultations and advice. Or they themselves may not be sufficiently informed about the details of the process innovation. Particularly in this constellation, 
a delegative-participative leadership style may enhance implementation success because the subordinate thus receives the opportunity and the legitimization to help himself or herself in any way that appears expedient. Again, this would mean that delegative-participative leadership is not a buffer against the risks entailed by high levels of consultative-advisory leadership but rather acts as a countermeasure against the risks of a lack of consultative-advisory leadership.

\section{Limitations}

It is important to acknowledge the limitations of the present study. First, as is the case in most empirical studies of innovation, all constructs were measured retrospectively and may thus be affected by hindsight bias. Because one can assume that the degree of retrospective distortions will increase over time, the participants were asked to answer the questions with respect to more recent process innovations. We thus aimed to at least reduce the degree of retrospective distortions. To completely prevent hindsight bias effects however, longitudinal follow-up studies would be needed.

Second, the self-report data may be affected by common method bias (Podsakoff, MacKenzie, Lee, \& Podsakoff, 2003). To prevent this problem, it is typically recommended that studies include different groups of people (e.g., members of the steering committee, project directors, developers of innovations, and users of innovations), with each group evaluating different variables (e.g., the leadership style is rated by the subordinates, whereas the implementation success is rated by top managers or customers). However, Spector (2006) argued that the potential problem of common method variance may be exaggerated. He provided empirical evidence that calls into question the assumption that the self-report method by itself yields systematic variance that significantly inflates results.

Nevertheless, we have addressed this problem by calculating the structure across all items of the study. Confirmatory factor analyses with maximum likelihood extraction were used to assess the fit of the general factor ( $\mathrm{G}$ factor) model to the data in comparison to the subfactor model. If the model test confirmed the $\mathrm{G}$ factor model, this would indicate the presence of a common method bias. (In the confirmatory model tests, a correlation matrix was used as the starting matrix. The variances of the latent variables were fixed. All loadings and residuals were estimated freely.) However, the data did not support a $G$ factor model. Several fit indices show that the $G$ factor model does not fit the data (Adjusted Goodness-of-Fit Index $=.54$, Goodness-of-Fit
Index $=.64$, root mean square error of approximation $=$ $\left..25, \chi^{2}=392.91, p<.0001\right)$. By contrast, the threefactor model fits the data reasonably well (Adjusted Goodness-of-Fit Index $=.90$, Goodness-of-Fit Index $=$ .92 , root mean square error of approximation $=.04$, $\left.\chi^{2}=6380.01, p<.0001\right)$.

\section{Conclusions}

\section{Theoretical Conclusions}

Our initial reasoning for the mutual risk compensation effect of delegative-participative and consultativeadvisory leadership (Hypothesis 3) appears not to be valid in the context of process innovations, at least in this sample. This may be so because with respect to process innovations, the posited buffering effects occur not so much when the levels of the two leadership patterns are high but rather when the level of one of these leadership styles is low. In other words, neglecting either delegative-participative or consultativeadvisory leadership behavior entails specific risks, and these risks can be held in check by enacting high levels of the respective other leadership pattern.

On a theoretical level, this shows that not only the relationship between a particular leadership style and the implementation success of innovations merits consideration but that the dynamics resulting from the interplay of different sets of leadership behavior should also be analyzed. One important aspect to examine would be how different combinations of leadership patterns affect success. A better understanding of the interplay of different leadership styles presupposes a clear description of the risks entailed by both high levels and low levels of the respective leadership behaviors. The present study underscores the importance of this question by illustrating the theoretical and practical importance not only of the interactions of leadership behaviors but also of the specific form of these interaction effects. The absence of one of the two sets of leadership behaviors discussed earlier is apparently linked with specific risks that need to be compensated by the other complementary set of leadership measures to ensure high levels of success.

\section{Practical Conclusions}

With respect to practical implications, the present study indicates that the quality of the implementation of process innovations and thus the effectiveness and efficiency of the respective work unit are highest when leaders exhibit both delegative-participative and 
consultative-advisory leadership behavior simultaneously. Thus, leaders would be well advised to combine these leadership facets. If, for whatever reason, a leader is unable to provide both of these leadership aspects (i.e., both delegative-participative and consultativeadvisory leadership), the importance of the respective other complementary set of behaviors becomes all the more important during the implementation process. Thus, at the very least, a leader should enact high levels of one of these sets of leadership behaviors (i.e., either delegative-participative or consultative-advisory leadership). Ideally however, a leader should strive to employ a combination of these two leadership styles so that the specific risks entailed by one set of behaviors are compensated by the effects of the respective complementary leadership pattern and vice versa.

Our results offer important implications for both leadership and management (cf. Yukl, 2006). With respect to management however, we would argue at a higher level of abstraction. Specifically, our results indicate that in the effort to foster implementation success, a holistic management perspective is called for. That is, a company's management must not only anticipate the respective positive and negative effects of delegative-participative and consultative-advisory leadership but also needs to consider the effects of combinations of leadership patterns. This entails that management acknowledges the dynamics of leadership patterns-namely, their antagonistic and/or complementary effects.

The usefulness of such a management approach has already been established with respect to other outcome criteria (e.g., increasing innovation speed, fostering innovation quality, decreasing innovation costs, promoting team innovations, enhancing organizational change) (cf. Atuahene-Gima, 2003; Gebert, Boerner, \& Kearney, 2006; Quinn \& Cameron, 1988; Sheremata, 2000). We propose that this approach is also conducive to successfully implementing process innovations. Hence, we would advocate a greater emphasis on holistic leadership in management education and training programs.

\section{References}

Amabile, T. M., Conti, R., Coon, H., Lazenby, J., \& Herron, M. (1996). Assessing the work environment for creativity. Academy of Management Journal, 39, 1154-1184.

Anderson, N. R., \& King, N. (1993). Innovations in organizations. In C. I. Cooper \& I. T. Robertson (Eds.), International review of industrial and organizational psychology (Vol. 8, pp. 1-33). Chichester, UK: Wiley.
Atuahene-Gima, K. (2003). The effects of centrifugal and centripetal forces on product development speed and quality: How does problem solving matter? Academy of Management Journal, 46, 359-373.

Axtell, C. M., Holman, D. J., Unsworth, K. L., Wall, T. D., Waterson, P. E., \& Harrington, E. (2000). Shopfloor innovation: Facilitating the suggestion and implementation of ideas. Journal of Occupational and Organizational Psychology, 73, 265-285.

Bauer, T. N., \& Green, S. G. (1996). Development of leadermember exchange: A longitudinal test. Academy of Management Journal, 39, 1538-1567.

Brehm, J. W. (1966). Theory of psychological reactance. New York: Academic Press.

Brockner, J., \& Siegel, P. A. (1996). Understanding the interaction between procedural and distributive justice. The role of trust. In R. M. Kramer \& T. R. Tyler (Eds.), Trust in organizations: Frontiers of theory and research (pp. 390-413). Thousand Oaks, CA: Sage.

Burpitt, W. J., \& Bigoness, W. J. (1997). Leadership and innovation among teams. The impact of empowerment. Small Group Research, 28, 414-423.

De Dreu, C. K. W. (2006). When too little or too much hurts: Evidence for a curvilinear relationship between task conflict and innovation in teams. Journal of Management, 32, 83-107.

Flanagan, J. C. (1954). The critical incidents technique. Psychological Bulletin, 51, 327-358.

Frese, M., \& Zapf, D. (1994). Action as the core of work psychology: A German approach. In H. C. Triandis, M. D. Dunnette, \& L. M. Hough (Eds.), Handbook of industrial and organizational psychology (pp. 271-340). Palo Alto, CA: Consulting Psychologists Press.

Gebert, D., Boerner, S., \& Kearney, E. (2006). Cross-functionality and innovation in new product development teams: A dilemmatic structure and its consequences for the management of diversity. European Journal of Work and Organizational Psychology, 15, 431-458.

Jehn, K. (1995). A multimethod examination of the benefits and detriments of intragroup conflict. Administrative Science Quarterly, 40, 256-282.

Krause, D. E. (2004). Influenced-based leadership as a determinant of the inclination to innovate and of innovationrelated behaviors-An empirical investigation. Leadership Quarterly, 15, 79-102.

Krause, D. E., \& Kearney, K. (2006). The use of power in different contexts: Arguments for a context specific perspective. In C. A. Schriesheim \& L. L. Neider (Eds.), Power and influence in organizations. New empirical and theoretical perspectives. Research in management: Vol. 5 (pp. 59-86). Greenwich, CT: Information Age Publishing.

Lazarus, R. S. (1991). Emotion and adaptation. New York: Oxford University Press.

Lewis, L. K., \& Seibold, D. R. (1993). Innovation modification during intraorganizational adoption. Academy of Management Journal, 18, 322-354.

Manz, C. C., Bastien D. T., Hostager, T. J., \& Shapiro, G. L. (1989). Leadership and innovation: A longitudinal process view. In A. H. Van de Ven, H. L. Angle, \& M. S. Poole (Eds.), Research on the management of innovation: The Minnesota studies (pp. 613-636). New York: Harper \& Row. 
Mumford, M. D., Scott, G. M., Gaddis, B., \& Strange, J. M. (2002). Leading creative people: Orchestrating expertise and relationships. Leadership Quarterly, 13, 705-750.

Oldham, G. R., \& Cummings, A. (1996). Employee creativity: Personal and contextual factors at work. Academy of Management Journal, 39, 607-634.

Podsakoff, P. M., MacKenzie, S. B., Lee, J. Y., \& Podsakoff, N. P. (2003). Common method biases in behavioral research: A critical review of the literature and recommended remedies. Journal of Applied Psychology, 88, 879-903.

Quinn, R. E., \& Cameron, K. S. (Eds.) (1988). Paradox and transformation: Toward a theory of change in organizations and management. Cambridge, MA: Ballinger.

Scott, S. G., \& Bruce, R. A. (1998). Following the leader in R\&D: The joint effect of subordinate problem-solving style and leadermember relations on innovative behavior. IEEE Transactions on Engineering Management, 45, 3-10.

Sheremata, W. (2000). Centrifugal and centripetal forces in radical new product development under time pressure. Academy of Management Review, 25, 398-408.

Spector, P. E. (2006). Method variance in organizational research. Truth or urban legend? Organizational Research Method, 9, 221-232.

Tierney, P., Farmer, S. M., \& Graen, G. B. (1999). An examination of leadership and employee creativity: The relevance of traits and relationships. Personnel Psychology, 52, 591-618.

Tyler, T. R., Degoey, P., \& Smith, H. (1996). Understanding why the justice of group procedures matters: A test of the psychological dynamics of the group-value model. Journal of Personality and Social Psychology, 70, 913-930.

West, M. (2002). Sparkling fountains or stagnant ponds: An integrative model of creativity and innovation implementation within groups. Applied Psychology: An International Review, 51, 355-386.

Yukl, G. (2006). Leadership in organizations (6th ed.). Upper Saddle River, NJ: Prentice Hall.

Diana E. Krause, $\mathrm{PhD}$, is an assistant professor of organizational behavior and human resource management at the University of Western Ontario (Canada). Her research focuses on leadership, power, influence, and trust in organizations; innovation and creativity; and assessment centers.

Eric Kearney, $\mathrm{PhD}$, is a researcher and lecturer at Technical University of Berlin. His research interests include transformational leadership, team innovativeness, diversity management, and attitude change.

Diether Gebert is a professor of organizational behavior at the Korea National University Business School, Seoul. His research includes leadership, organizational change and organizational development, philosophical aspects of organizations, diversity management, and team performance. 